\title{
Disruption of Dorsolateral But Not Ventrolateral Prefrontal Cortex Improves Unconscious Perceptual Memories
}

\author{
Taraz G. Lee, ${ }^{1}$ Robert S. Blumenfeld, ${ }^{2}$ and Mark D’Esposito ${ }^{2,3}$ \\ ${ }^{1}$ Department of Psychological and Brain Sciences, University of California at Santa Barbara, Santa Barbara, California 93106, and ${ }^{2} \mathrm{Helen}$ Wills Neuroscience \\ Institute and ${ }^{3}$ Department of Psychology, University of California at Berkeley, Berkeley, California 94110
}

\begin{abstract}
Attentive encoding often leads to more accurate responses in recognition memory tests. However, previous studies have described conditions under which taxing explicit memory resources by attentional distraction improved perceptual recognition memory without awareness. These findings lead to the hypothesis that explicit memory processes mediated by the prefrontal cortex (PFC) can interfere with memory processes necessary for implicit recognition memory. The present study directly tested this hypothesis by applying transcranial magnetic stimulation separately over either dorsolateral (DLPFC) or ventrolateral PFC (VLPFC) in humans before performance of a visual memory task. Disruption of DLPFC function led to improvement in recognition accuracy only in responses in which the participant's awareness of memory retrieval was absent. However, disruption of VLPFC function led to subtle shifts in recollection and familiarity accuracy. We conclude that explicit memory processes mediated by the DLPFC can indirectly interfere with implicit recognition memory.
\end{abstract}

\section{Introduction}

Several influential studies demonstrating that explicit memory, and not implicit memory, is impaired in patients with amnesia have led to the dominant view that implicit and explicit memory are mediated by distinct brain networks (Cohen and Squire, 1980; Graf and Schacter, 1985; Gabrieli et al., 1995). Subsequently, many studies provided further evidence that explicit and implicit memory are distinct at both the behavioral and neural levels (Gabrieli, 1998; Squire, 2004; Schott et al. 2005), although with some evidence of overlap (Wig et al., 2005; Turk-Browne et al., 2006; Henke 2010). Unfortunately, the potentially competitive interaction between these two systems remains underspecified (Dew and Cabeza, 2011).

Previously, two studies described conditions under which taxing explicit memory resources improved recognition memory without awareness (Voss et al., 2008; Voss and Paller, 2009). When participants encoded to-be-remembered stimuli during a divided attention condition, recognition memory was highly accurate despite a lack of confidence (guessing). Since divided attention at encoding typically disrupts explicit memory (and implicit conceptual memory), but not implicit perceptual memory (Mulligan, 1998), these results suggest that implicit memory can aid performance on recognition tests, and in certain contexts explicit memory processes can interfere with implicit memory

\footnotetext{
Received Dec. 10, 2012; revised July 7, 2013; accepted July 11, 2013.

Author contributions: T.G.L., R.S.B., and M.D. designed research; T.G.L. and R.S.B. performed research; T.G.L. analyzed data; T.G.L., R.S.B., and M.D. wrote the paper.

This work was supported by the National Institutes of Health Grants MH63901 and NS40813. We thank J. Lim for his help with behavioral testing and programming the behavioral task and J. Riddle for part of the data collection. We thank Paul Reber and Antonio Gisbert for the software used to generate the task stimuli.

Correspondence should be addressed to Taraz G. Lee, Psychology East, University of California Santa Barbara, Santa Barbara, CA 93106-9660. E-mail: tarazlee@gmail.com.

DOI:10.1523/JNEUROSCI.5652-12.2013

Copyright $\odot 2013$ the authors $\quad 0270-6474 / 13 / 3313233-05 \$ 15.00 / 0$
}

processes. Furthermore, explicit recognition in this task coincided with positive ERP responses in anterior electrode clusters above prefrontal cortex (PFC), whereas implicit recognition ("guess" responses) were associated with negative ERP responses similar to those found in implicit perceptual priming (Voss and Paller, 2009).

Patients with frontal lobe damage often have subtle explicit memory deficits but preserved implicit memory (Shimamura, 1995; Ranganath and Knight, 2002). Additionally, neuroimaging studies of long-term memory (LTM) have consistently shown that enhanced PFC activity during encoding leads to greater accuracy during tests of recall or recognition (Paller and Wagner, 2002). Based on these findings, the contribution of PFC function to LTM performance is thought to be through cognitive control mechanisms such as the selection and organization of to-beremembered information at encoding and retrieval (Blumenfeld and Ranganath, 2007).

Here, we test the hypothesis that PFC-mediated top-down control processes that support explicit memory can indirectly interfere with implicit memory. Implicit perceptual memory is thought to rely on the fluency in reprocessing information in visual cortex (Wiggs and Martin, 1998), but if PFC activity related to explicit memory leads to altered processing of visual information, then implicit memory could be harmed. Prior work has demonstrated functional dissociations between the contribution of dorsolateral PFC (DLPFC) and ventrolateral PFC (VLPFC) to long-term memory (Blumenfeld and Ranganath, 2007; Murray and Ranganath, 2007). Thus, we used continuous theta-burst transcranial magnetic stimulation (TMS) to disrupt the function of either DLPFC or VLPFC in humans before the performance of the recognition memory task used by Voss and Paller (2009). Applying TMS to disrupt function in two separate PFC regions provides a direct causal test of whether explicit memory processing 
by the PFC competitively exerts control over sensory resources, thereby indirectly harming more transfer-appropriate implicit memory processes. This test may also provide evidence for the type of attentional processes responsible for this interference.

\section{Materials and Methods}

Participants. Thirty-five right-handed subjects (16 males; ages 18-29) participated in the main experiment. Participants were randomly assigned to one of two groups. Each participant underwent two separate experimental TMS sessions on separate days. Participants in the VLPFC group (16 participants) received stimulation to this region in one session and stimulation to the vertex of the scalp in a separate session to control for any nonspecific effects of TMS. Likewise, participants in the DLPFC group (19 participants) received stimulation to this region and to vertex in separate sessions. The order of stimulation (frontal vs vertex) was counterbalanced across participants in each group. Data for two participants in the DLPFC group were excluded because their memory accuracy did not exceed chance levels, so it could not be determined whether they were performing the task or responding at random.

Stimuli. Visual stimuli consisted of 14 sets of 12 perceptually paired kaleidoscope images (336 total). Images were created by overlaying three opaque hexagons of different colors and bisecting and randomly deflecting the sides of each three times. The same three colors were used for all images in each set. Perceptual matching for each pair was achieved by using the same colors, using similar deflection angles, and visual inspection by a research assistant.

Task design. Ten minutes following the administration of TMS, kaleidoscope images were presented to individuals in five separate study-test blocks. During the encoding period of each block, 12 target images chosen randomly from each perceptually matched pair were presented for $200 \mathrm{~ms}$ each with a $1.5 \mathrm{~s}$ interstimulus interval (Fig. 1a). A forced-choice recognition test was administered after a $45 \mathrm{~s}$ delay upon the conclusion of the encoding period. Each test trial consisted of one of the 12 targets studied during encoding and a perceptually matched foil alternately presented three times for $500 \mathrm{~ms}$ each with a $1 \mathrm{~s}$ interstimulus interval (Fig. $1 b$ ). Participants were instructed to visually compare the two stimuli and to select the previously studied item using a button press.

Immediately following each recognition decision, participants were presented with a metamemory prompt that asked them to report their subjective awareness of memory retrieval using a remember/know procedure. Participants were instructed to give a remember response if they were able to retrieve a specific detail about the item or the context in which they saw the item during study. Know responses signified confident responses without the recollection of any specific details from encoding. Guess responses indicated a lack of any feelings of familiarity when participants chose randomly. Importantly, to ensure that guess responses were relatively frequent, participants were told that guess responses would be common and that they should not hesitate if they thought that they were guessing (Jeneson et al., 2010; Voss and Paller, 2010). Before the experimental blocks, participants practiced the task with a miniblock that consisted of only three study items and a corresponding forced-choice recognition test.

The recognition memory task used in this experiment was specifically designed to provoke responses based on implicit memory in the absence of explicit memory (Voss et al., 2008). As a result, the semantic and elaborative encoding and retrieval strategies, which are strongly associated with PFC activity (Wagner et al., 2001) as well as with explicit memory (Yonelinas, 2002), could not be used effectively for this task. While recognition tests have usually been deployed to measure explicit memory, the metamemory responses collected in this task allow the examina- tion of the contribution of implicit visual memory to recognition performance.

Frontal stimulation targets. Both PFC TMS targets were chosen based on previously reported activations from functional magnetic resonance imaging (fMRI) studies using standard-space coordinates from the Montreal Neurological Institute (MNI) brain. The MNI-space coordinate for VLPFC stimulation was based on a location published in the study by Wagner et al. (1998). This study found that VLPFC activity (centered on $-51,25,12$ ) during encoding correlated with subsequent explicit item recognition. Here we used a similar coordinate that was situated more clearly on the cortical surface $(-53,28,12)$. The DLPFC stimulation site was based on a local maximum from a study by Blumenfeld et al. (2011). This region (centered on $-44,35,26$ ) correlated with subsequent explicit LTM for interitem relational information. We used a similar coordinate that was positioned slightly more dorsal $(-43,35,30)$. The coordinates chosen were at least $20 \mathrm{~mm}$ apart to ensure that stimulation to one site did not affect function in the other site. Ten millimeter spherical masks were constructed at the two sites in MNI space and reversed normalized into individual subject space using structural MR images acquired previously for each participant (Fig. 2). These masks as well as the structural MR images were used for frameless stereotaxy (see below, Transcranial magnetic stimulation procedure). Given the evidence for the left lateral PFC's involvement in semantic and elaborative control processes in memory tasks, stimulation in this study was confined to the left hemisphere.

Transcranial magnetic stimulation procedure. Electromyography was recorded using electrodes attached to the right first dorsal interosseous (FDI) muscle of the dominant hand. TMS was applied using a hand-held figure-eight coil with an outer winding diameter of $70 \mathrm{~mm}$ (Magstim). All pulses were delivered using a Magstim rapid stimulator connected to four booster modules that produce biphasic pulses. The motor cortical hand area was defined as the location on the scalp where magnetic stimulation produced the largest motor-evoked potential (MEP) from the relaxed contralateral FDI. The stimulation intensity was defined as $80 \%$ of the active motor threshold (AMT) of the participant. AMT was defined as the minimum intensity required to produce an MEP on at least 5 of 10 trials from the contralateral FDI while the participant was maintaining a voluntary contraction of $20 \%$ of maximum in the FDI.

The stimulation targets were localized using Brainsight, a computerized frameless stereotaxic system (Rogue Research). Reflective markers were attached to the coil and the participant, so that relative positions of the coil to the head (and MR image) could be tracked in real time, allowing precise positioning of the coil with respect to previously chosen cortical locations.

The TMS protocol used in the current study was identical to the continuous theta burst procedure described by Huang et al. (2005) and has 

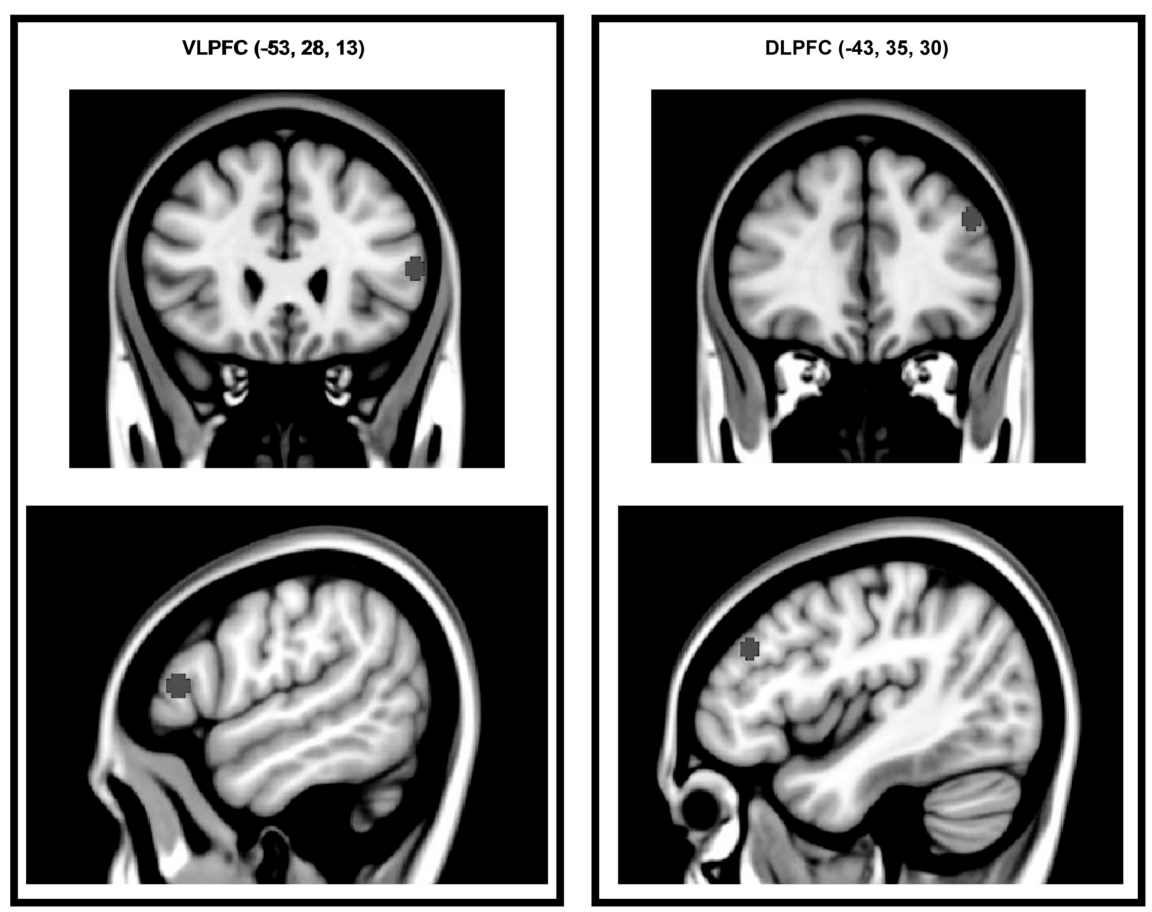

Figure 2. Frontal cortex TMS targets. All TMS targets were reverse normalized into each participant's native space for frameless stereotaxy. Targets presented here are shown on a template brain in MNI space.

been shown to depress activity in the stimulated region for 20-60 min following stimulation, depending on the number of pulses administered. Stimulation consisted of $50 \mathrm{~Hz}$ trains of three TMS pulses repeated every 200 ms continuously over a period of 30 s (450 pulses total). Because study and test blocks occurred in quick succession, it is likely that the effect of TMS was equivalent for each study-test pair.

Data analysis. Participants' accuracy rates were computed separately for each session for each metamemory category (remember, know, and guess). Additionally, meta- $d^{\prime}$ was calculated for each participant for each session to quantify metacognitive sensitivity. Metacognitive, or "type 2," sensitivity measures the observer's ability to use confidence ratings to discriminate between their own correct and incorrect stimulus classifications. Meta- $d^{\prime}$ is a previously developed measure of type 2 sensitivity that is not influenced by response bias or overall classification (type 1) sensitivity (Maniscalco and Lau, 2012). Remember, know, and guess responses were assumed to correspond with high, medium, and low confidence, respectively, for this analysis.

The effect of TMS on the task was evaluated by a repeated measures ANOVA on the accuracy with the stimulation site (vertex vs frontal) and metamemory category as within-subject factors and group (DLPFC vs VLPFC) as between-subject factors. Separate ANOVAs were run on the proportion of each metamemory response given by the participants. Post hoc two-tailed $t$ tests were used to compare results between the two stimulation conditions where appropriate.

\section{Results}

A main effect of metamemory response $\left(F_{(1,30)}=194.84, p<\right.$ $\left.0.001, \eta_{p}^{2}=0.867\right)$ was found whereby participants were the most accurate overall when responding "remember" and were the least accurate when making a "guess." Additionally, a significant linear two-way TMS condition by group interaction $\left(F_{(1,30)}=5.484\right.$, $p<0.05, \eta_{p}^{2}=0.155$ ) was found, indicating that the effect of frontal TMS differed between the two groups. The TMS condition by metamemory response by group interaction was also significant suggesting that accuracy for the different metamemory categories also differed as a function of group $\left(F_{(1,30)}=3.987, p<\right.$ $\left.0.05, \eta_{p}^{2}=0.117\right)$. Within the DLPFC group there was a signifi- cant main effect of TMS location whereby overall accuracy was greater following DLPFC stimulation $\left(F_{(1,16)}=\right.$ 4.887, $p<0.05, \eta_{p}^{2}=0.234$; VLPFC, $\left.F_{(1,15)}=1.23, p>0.1, \eta_{p}^{2}=0.081\right)$. Analyses revealed significant two-way interactions of TMS condition and metamemory response in the VLPFC group $\left(F_{(1,15)}=\right.$ 7.178, $\left.p<0.05, \eta_{p}^{2}=0.339\right)$ and a trend toward this interaction in the DLPFC $\left(F_{(1,16)}=3.429, p<0.1, \eta_{p}^{2}=0.177\right)$. Accuracy was significantly greater for guess responses after DLPFC stimulation than after vertex stimulation $\left(t_{(16)}=2.26\right.$, $p<0.05, d=0.287)$, and also significantly greater than chance performance $\left(t_{(16)}=\right.$ 3.47, $p<0.005, d=0.405)$, suggesting that implicit memory was improved following interference to explicit processes mediated by the DLPFC (Fig. 3a). Accuracy did not significantly differ after DLPFC stimulation for remember $\left(t_{(15)}=\right.$ $0.44, p>0.1)$. or know responses $\left(t_{(15)}=\right.$ $1.61, p>0.1)$.

In the VLPFC group there was no difference in overall accuracy $\left(t_{(15)}=\right.$ $-0.148, p>0.5)$, but the crossover interaction with metamemory response was driven by slightly more accurate know responses after frontal stimulation as compared to vertex stimulation, yet less accurate remember $\left(F_{(1,15)}=7.43, p<0.05, \eta_{p}^{2}=\right.$ $0.347)$ and guess responses $\left(F_{(1,15)}=4.37, p=0.055, \eta_{p}^{2}=0.347\right.$; Fig. $3 b)$. This suggests that although VLPFC stimulation did not change overall accuracy, it impacted the relative attribution of accurate responses, lending to a shift toward more accurate familiar responses.

There was no significant change in the proportion of each metamemory response (Fig. 4), nor were there significant differences in meta- $d^{\prime}$ between vertex stimulation and frontal stimulation in either the VLPFC (means, $1.40,1.27 ; t_{(15)}=0.33$, $p>0.5$ ) or the DLPFC group (means, $1.31,1.11 ; t_{(16)}=0.754$, $p>0.45)$. Enhanced performance following DLPFC stimulation was unlikely due to a shift in response confidence, but that, when explicit processing was not useful at retrieval (remember and know responses), the effectiveness of implicit memory processing (guess responses) was improved.

\section{Discussion}

We often need to override and alter reflexive actions to achieve our goals. Unsurprisingly, most studies find that the PFCmediated cognitive control processes that guide our actions based on goals, rules, or intentions are advantageous for successful explicit and implicit memory. In the current study, a forced-choice recognition task was used with remember-know judgments that allowed for the examination of both explicit and implicit contributions to successful recognition memory. Interfering with VLPFC function with TMS led to a subtle decrease in accuracy for items endorsed as recollected and a subtle increase for items endorsed as familiar, suggesting a change in explicit memory strength as measured by recognition confidence. However, we also found evidence that certain cognitive control processes mediated by the PFC can indirectly impact implicit memory function. By temporarily disrupting DLPFC function using TMS, we 

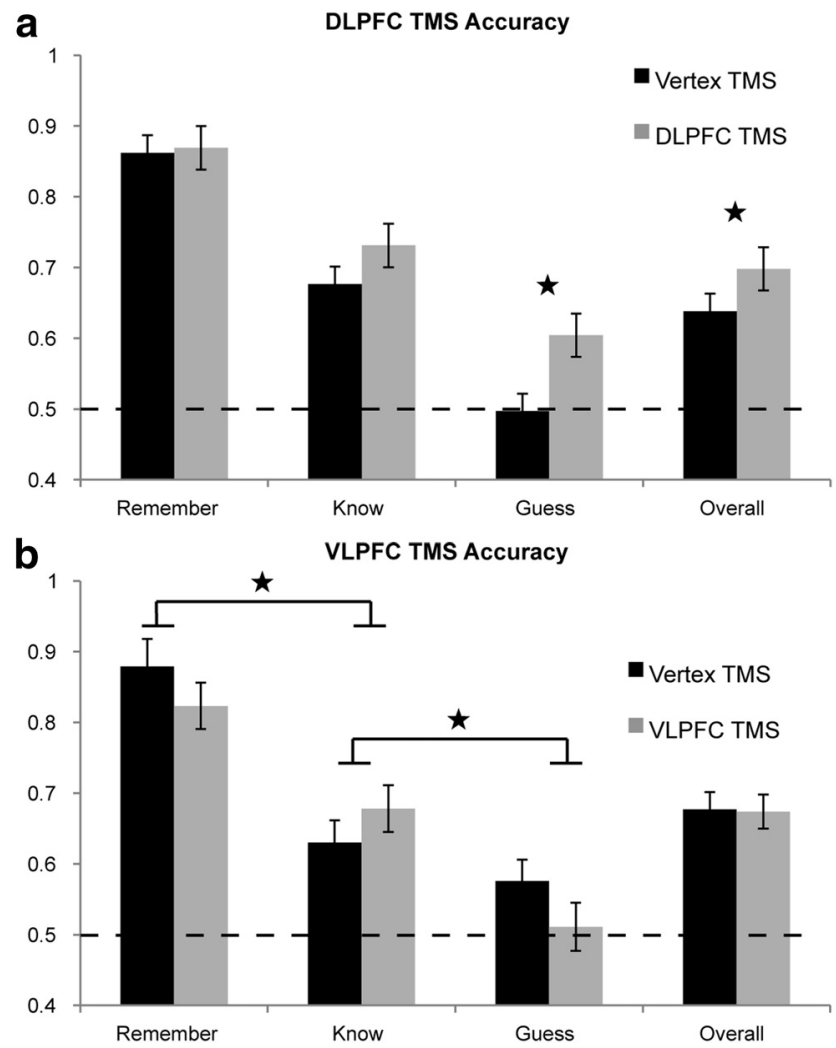

Figure 3. Recognition accuracy. $\boldsymbol{a}$, Participants were more accurate in their recognition responses when they indicated that they had no awareness of memory retrieval following DLPFC stimulation compared to vertex stimulation. $\boldsymbol{b}$, VLPFC stimulation led to a relative decrease in the accuracy of recollection responses and a relative increase in accuracy of familiar responses when compared to vertex stimulation. ${ }^{*} p<0.05$ (bar represents the metamemory by TMS site interaction).

enhanced recognition memory performance when participants had to rely on implicit perceptual memory (as indexed by guess responses).

The observed improvement in accuracy for guess responses following DLPFC stimulation suggests that DLPFC-mediated control processes are counterproductive for this task and may bias resources away from more transfer-appropriate processing at the time of encoding. DLPFC activity at encoding has been linked to interitem relational or organizational processing (Blumenfeld and Ranganath, 2006). In the present task, given the high degree of perceptual similarity among the studied items and the brief presentation time, engaging in relational processing during encoding is an ineffective strategy that potentially takes resources away from more transfer-appropriate perceptual implicit encoding. Thus, disrupting DLPFC during encoding will decrease its efficacy and allow perceptual implicit or item-specific strategies to have a greater impact on performance. Similarly, several studies have found enhanced DLPFC activity for subsequently forgotten items at test when relational processing is task-irrelevant (Otten and Rugg, 2001; Wagner and Davachi, 2001; Daselaar et al., 2004). These findings along with our own results suggest that the disengagement of cognitive control processes mediated by the DLPFC at encoding may be responsible for the improved performance observed here.

It is also possible that disrupted DLPFC-mediated relational processing during retrieval may also have contributed to the paradoxical increase in guessing accuracy given the extended duration of effects of stimulation. Two-alternative forced choice a

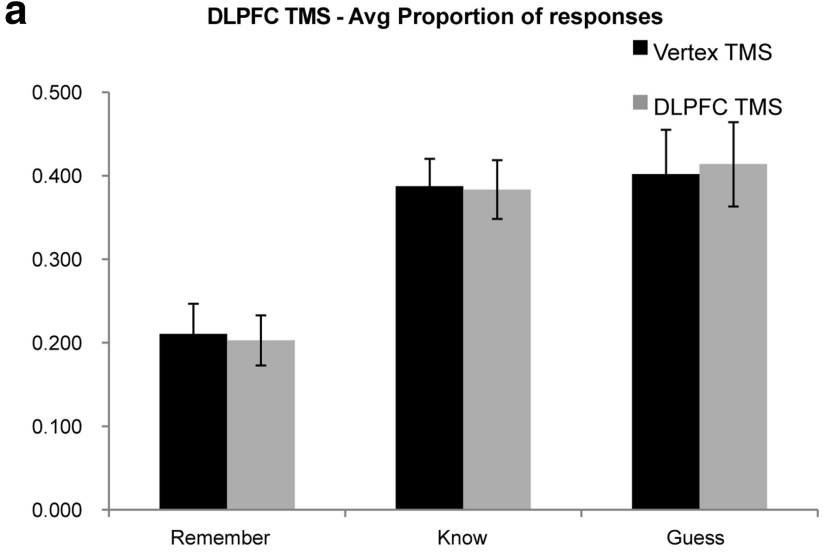

b

VLPFC TMS - Avg Proportion of Responses

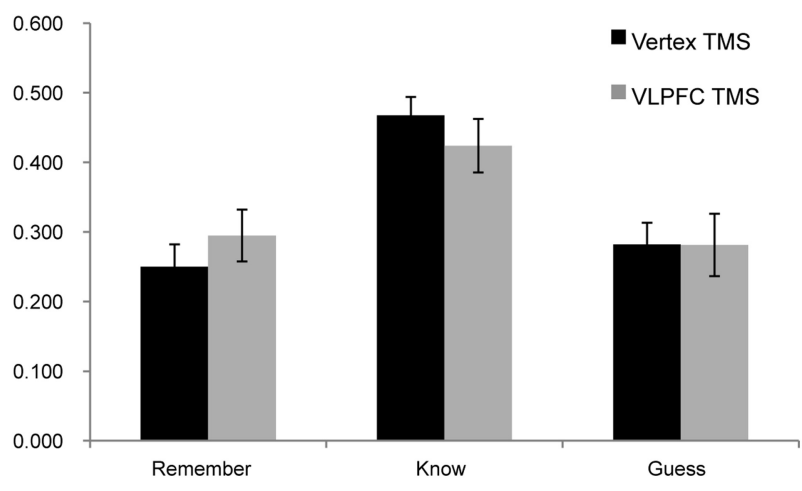

Figure 4. Average proportion of metamemory responses. $\boldsymbol{a}, \boldsymbol{b}$, Neither ( $\boldsymbol{a})$ DLPFC stimulation nor $(\boldsymbol{b})$ VLPFC stimulation led to a change in the frequency of each metamemory response.

recognition paradigms, like the one used here, allow for participants to engage in a strategy of relating and comparing the features of the test items with each other to help select the correct "old" item in the absence of recollection. While these DLPFCmediated relational strategies are often helpful, the stimuli in this task were chosen to be highly perceptually similar specifically to make this process difficult and potentially harmful to success. Thus, impaired DLPFC function during retrieval may allow for a greater contribution of implicit memory processes during the test phase in the absence of recollection.

Previous explanations of paradoxical memory enhancements during cognitively demanding implicit memory tasks performed under divided attention conditions (Reber, 1989; Laufer, 2008; Voss et al., 2008; Filoteo et al., 2010) have focused on the competition between implicit and explicit memory systems without a clear account of the cognitive and neural mechanisms responsible for this interaction. Prior work has shown that DLPFC, but not VLPFC, is particularly sensitive to divided attention during encoding (Uncapher and Rugg, 2005). By disrupting DLPFC activity, we were able to mimic the results of previous studies (Voss et al., 2008; Voss and Paller, 2009) showing that divided attention at encoding similarly improves performance on this task without awareness. Our results provide a mechanistic explanation for this paradoxical literature by suggesting that organizational and strategic processes supported by the DLPFC can indirectly interfere with implicit memory.

In contrast to DLPFC disruption, VLPFC TMS led to a subtle shift in confidence and accuracy toward familiar items and away from recollected items with no measurable improvement in implicit memory (as measured by guess responses). Increased 
VLPFC activity at encoding has consistently been associated with successful memory performance, and specifically with the various item and feature selection processes important for LTM (Badre and Wagner, 2007). Similar to our current findings, Kahn et al. (2005) also observed changes in explicit memory strength (as indexed by changes in recognition confidence) following TMS disruption of VLPFC. Additionally, several groups have found that encoding processes mediated by the VLPFC may actually aid certain types of implicit memory function (Köhler et al., 2004; Wig et al., 2005; Turk-Browne et al., 2006). Our results are in line with this previous work that suggests the VLPFC's role in attentional selection may be necessary for encoding processes that are necessary for both successful implicit and explicit memory.

Given our current results, however, we cannot rule out the possibility that VLPFC TMS led to a shift in criteria for the different metamemory responses. Several PFC regions have been implicated in metacognitive awareness both visual discrimination tasks and in different aspects of metamemory (Fleming and Dolan, 2012). While we did not find any significant differences in meta-d' or the proportion of responses in each metamemory category, it remains plausible that a criterion shift in metamemory reporting might have contributed to the findings presented here.

\section{References}

Badre D, Wagner AD (2007) Left ventrolateral prefrontal cortex and the cognitive control of memory. Neuropsychologia 45:2883-2901. CrossRef Medline

Blumenfeld RS, Ranganath C (2006) Dorsolateral prefrontal cortex promotes long-term memory formation through its role in working memory organization. J Neurosci 26:916-925. CrossRef Medline

Blumenfeld RS, Ranganath C (2007) Prefrontal cortex and long-term memory encoding: An integrative review of findings from neuropsychology and neuroimaging. Neuroscientist 13:280-291. CrossRef Medline

Blumenfeld RS, Parks CM, Yonelinas AP, Ranganath C (2011) Putting the pieces together: the role of dorsolateral prefrontal cortex in relational memory encoding. J Cogn Neurosci 23:257-265. CrossRef Medline

Cohen NJ, Squire LR (1980) Preserved learning and retention of patternanalyzing skill in amnesia: dissociation of knowing how and knowing that. Science 210:207-210. CrossRef Medline

Daselaar SM, Prince SE, Cabeza R (2004) When less means more: deactivations during encoding that predict subsequent memory. Neuroimage 23: 921-927. CrossRef Medline

Dew IT, Cabeza R (2011) The porous boundaries between explicit and implicit memory: behavioral and neural evidence. Ann N Y Acad Sci 1224: 174-190. CrossRef

Filoteo JV, Lauritzen S, Maddox WT (2010) Removing the frontal lobes: the effects of engaging executive functions on perceptual category learning. Psychol Sci 21:415-423. CrossRef Medline

Fleming SM, Dolan RJ (2012) The neural basis of metacognitive ability. Phil Trans R Soc B Biol Sci 367:1338-1349. CrossRef

Gabrieli JD (1998) Cognitive neuroscience of human memory. Annu Rev Psychol 49:87-115. CrossRef Medline

Gabrieli JD, Fleischman DA, Keane MM, Reminger SL, Morrell F (1995) Double dissociation between memory systems underlying explicit and implicit memory in the human brain. Psychol Sci 6:76-82. CrossRef

Graf P, Schacter DL (1985) Implicit and explicit memory for new associations in normal and amnesic subjects. J Exp Psychol Learn Mem Cogn 11:501-518. Medline

Henke K (2010) A model for memory systems based on processing modes rather than consciousness. Nat Rev Neurosci 11:523-532. Medline

Huang YZ, Edwards MJ, Rounis E, Bhatia KP, Rothwell JC (2005) Theta burst stimulation of the human motor cortex. Neuron 45:201-206. CrossRef Medline

Jeneson A, Kirwan CB, Squire LR (2010) Recognition without awareness: an elusive phenomenon. Learn Mem 17:454-459. CrossRef
Kahn I, Pascual-Leone A, Theoret H, Fregni F, Clark D, Wagner AD (2005) Transient disruption of ventrolateral prefrontal cortex during verbal encoding affects subsequent memory performance. J Neurophsyiol 94:688698. CrossRef

Köhler S, Paus T, Buckner RL, Milner B (2004) Effects of left inferior prefrontal stimulation on episodic memory formation: a two-stage fMRIrTMS study. J Cogn Neurosci 16:178-188. CrossRef Medline

Laufer Y (2008) Effect of cognitive demand during training on acquisition, retention and transfer of a postural skill. Hum Mov Sci 27:126-141. CrossRef Medline

Maniscalco B, Lau H (2012) A signal detection theoretic approach for estimating metacognitive sensitivity from confidence ratings. Conscious Cogn 21:422-430. CrossRef Medline

Mulligan NW (1998) The role of attention during encoding in implicit and explicit memory. J Exp Psychol Learn Mem Cogn 24:27-47. Medline

Murray LJ, Ranganath C (2007) The dorosolateral prefrontal cortex contributes to successful relational memory encoding. J Neurosci 27: 5515-5522. CrossRef Medline

Otten LJ, Rugg MD (2001) When more means less: neural activity related to unsuccessful memory encoding. Curr Biol 11:1528-1530. CrossRef Medline

Paller KA, Wagner AD (2002) Observing the transformation of experience into memory. Trends Cogn Sci 6:93-102. CrossRef Medline

Ranganath C, Knight RT (2002) Prefrontal cortex and episodic memory: integrating finding from neuropsychology and event-related functional neuroimaging. In: Memory encoding and retrieval: a cognitive neuroscience perspective (Parker A, Wilding E, Bussey T, eds), pp 83-99. New York: Psychology.

Reber AS (1989) Implicit learning and tacit knowledge. J Exp Psychol 118: 219-235. CrossRef

Schott BH, Henson RN, Richardson-Klavehn A, Becker C, Thoma V, Heinze H, Duzel E (2005) Redefining implicit and explicit memory: the functional neuroanatomy of priming, remembering, and control of retrieval. Proc Natl Acad Sci U S A 102:1257-1262. CrossRef Medline

Shimamura AP (1995) Memory and the prefrontal cortex. Ann N Y Acad Sci 769:151-159. CrossRef

Squire LR (2004) Memory systems of the brain: a brief history and current perspective. Neurobiol Learn Mem 82:171-177. CrossRef Medline

Turk-Browne NB, Yi DJ, Chun MM (2006) Linking implicit and explicit memory: common encoding factors and shared representations. Neuron 49:917-927. CrossRef Medline

Uncapher MR, Rugg MD (2005) Effects of divided attention on fMRI correlates of memory encoding. J Cogn Neurosci 17:1923-1935. Medline

Voss JL, Baym CL, Paller KA (2008) Accurate forced-choice recognition without awareness of memory retrieval. Learn Mem 15:454-459. CrossRef Medline

Voss JL, Paller KA (2009) An electrophysiological signature of unconscious recognition memory. Nat Neurosci 12:349-355. CrossRef Medline

Voss JL, Paller KA (2010) What makes recognition without awareness appear to be elusive? Strategic factors that influence the accuracy of guesses. Learn Mem 17:460-468. CrossRef Medline

Wagner AD, Davachi L (2001) Cognitive neuroscience: forgetting of things past. Curr Biol 11:R694-R697. Medline

Wagner AD, Schacter DL, Rotte M, Koutsaal W, Maril A, Dale AM, Rosen BR, Buckner RL (1998) Building memories: remembering and forgetting of verbal experiences as predicted by brain activity. Science 281:1188-1191. CrossRef Medline

Wagner AD, Maril A, Bjork RA, Schacter DL (2001) Prefrontal contributions to executive control: fMRI evidence for functional distinctions within lateral prefrontal cortex. Neuroimage 14:1337-1347. CrossRef Medline

Wiggs CL, Martin A (1998) Properties and mechanisms of perceptual priming. Curr Opin Neurobiol 8:227-233. CrossRef Medline

Wig GS, Grafton ST, Demos KE, Kelley WM (2005) Reductions in neural activity underlie behavioral components of repetition priming. Nat Neurosci 8:1228-1233. Medline

Yonelinas AP (2002) The nature of recollection and familiarity: a review of 30 years of research. J Mem Lang 46:441-517. CrossRef 